\title{
Solar collector angle optimization for maximum air flow rate in the solar chimney
}

\author{
Fei Cao, Yufei Mao, Qingjun Liu, Hong Xiao and Tianyu Zhu \\ College of Mechanical and Electrical Engineering, Hohai University, PR China \\ For corresponding: xjtu-bigboy@163.com
}

\begin{abstract}
Keywords: Solar collector angle, maximum air flow rate, solar chimney, system optimization, solar energy.
\end{abstract}

\begin{abstract}
The solar chimney and the solar collector are two important components in solar energy engineering. Solar collector is mainly used to gather solar energy. Correspondingly, the angle at which the solar collector receives the maximum solar radiation is its core parameter. While for the solar chimney, solar radiation is absorbed by the air inside the solar collector to generate air flow into the chimney. Thus, there is a solar collector tilted angle at which the airflow inside the chimney reaches the maximum. There are many reports on the maximum solar radiation (MSR) in the solar collector. However, there are few studies on the maximum air flow (MAF) in the solar chimney. In this study, a mathematical model is first established for the solar chimney system. Then, an experimental setup is established to evaluate the MAF angle for the solar chimney. The solar chimneys under MSR and MAF angles are finally analyzed and compared. The results mainly show that in solar collector system with MAF angle, with the collector angle increasing, although the air temperature rise decreases gradually at the collector outlet, the air flow rate generally decreases after a long-term increase. And taking the solar radiation at Lanzhou City as a case study, the MAF angle was $60^{\circ}$, whereas the MSR angle was $30^{\circ}$.
\end{abstract}

\section{Introduction}

Nowadays, sustainable development has been accepted as a worldwide focus. Environmental sustainable development is proposed mainly to deal with the air pollution, the water poison and the atmosphere protection. Solar energy, one of the most promising renewable and sustainable energy, has drawn high attention all over the world. Several solar energy technologies, such as the solar collector, the solar chimney, the solar Trombe, etc. have been industrially utilized in solar energy systems. Among them, the surface receiving the solar energy is the energy source for the system. Correspondingly, the surface angle is of high importance to the solar energy systems. For the solar collector, the solar energy entering the collector area is a core parameter. Whereas for the solar chimney, the air flow rate is of high importance. There are many studies concentrating on optimizing the solar collector angles to absorb maximum solar radiation (MSR). El-Maghlany et al. analyzed the orientation of the greenhouses for maximum capture of solar energy in North Tropical Region[1]. Abbassi and Dehmani carried out experimental and numerical study on thermal performance of an unvented Trombe wall associated with internal thermal fins[2]. Shojaeizadeh et al. investigated an $\mathrm{Al}_{2} \mathrm{O}_{3}$-water nanofluid based flat-plate solar collectors[3]. With respect to the solar chimney, conventional solar chimneys are laid on the center of a horizontal solar collector or solar Trombe[4]. Inclining the tilted angle of the solar collector or solar Trombe would increase the incident solar radiation on its surface but too large tilted angles would lead to the decrease of air flow rate. The angle at which the maximum air flow (MAF) is generated in the solar chimney has rarely been studied in the literature[4]. Considering this, purpose of this study is to make clear the difference of the MSR and MAF angles for the solar chimney system. Main tasks in this study can be summarized as: 1) to establish a mathematical model through basic heat transfer and solar radiation principle; 2) to develop an experimental setup to analyze the MSR and MAF angles; and 3) to compare the MSR and MAF angles for on specific location. 


\section{Mathematical model}

\section{Solar collector}

The solar energy received by the collector is transmitted through a transparent cover and absorbed by the ground. Schematic of thermal balance in the collector is shown in Fig.1. The solar radiation absorbed by the glass cover is $S_{2}$ and the solar radiation absorbed by the ground is $S_{1}$. The cold air, with the temperature $T_{c}$, enters the collector and heated by the hot ground.

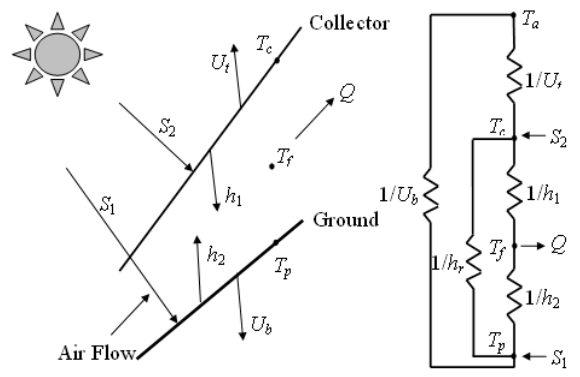

Fig. 1 Schematic of the heat transfer and the thermal balance in the solar collector Energy balance of the glass cover:

$$
S_{2}+U_{t}\left(T_{a}-T_{c}\right)+h_{r}\left(T_{p}-T_{c}\right)+h_{1}\left(T_{f}-T_{c}\right)=0
$$

Energy balance of the ground:

$S_{1}+U_{b}\left(T_{a}-T_{p}\right)+h_{2}\left(T_{f}-T_{p}\right)+h_{r}\left(T_{c}-T_{p}\right)=0$

Energy balance of the air in the collector:

$$
h_{1} A_{\text {coll }}\left(T_{c}-T_{f}\right)+h_{2} A_{\text {coll }}\left(T_{p}-T_{f}\right)=Q
$$

where, heat absorbed by the airflow $\mathrm{Q}$ is expressed as:

$$
Q=M C_{p}\left(T_{o}-T_{a}\right)
$$

\section{Chimney}

Pressure developed because of air density difference between inlet and outlet of the chimney is calculated as follows:

$$
\Delta P=\int_{\text {inlet }}^{\text {outlet }} g\left(\rho_{a}-\rho(z)\right) d z
$$

For a vertical adiabatic chimney, by integrating Eq. (5), we obtain:

$\Delta P_{\text {tot }}=\left(\rho_{a}-\rho_{o}\right) g H_{c h i}$

For the inclined solar collector, integrating Eq. (5) from the solar collector inlet to the chimney outlet, the total pressure produced in the chimney then could be expressed as[5,6]:

$$
\Delta P_{\text {tot }}=\left(\rho_{a}-\rho_{o}\right) g\left(H_{c h i}+\frac{1}{2} H_{c o l}\right)
$$

The generated pressure is consumed by the friction losses in the collector and chimney $\Delta \mathrm{P}_{\mathrm{f}}$, the kinetic loss at the chimney inlet $\Delta \mathrm{P}_{\text {in }}$ and the kinetic loss at the outlet $\Delta \mathrm{P}_{\text {out }}$. Thus, the next equation is obtained:

$$
\Delta P_{\text {tot }}=\Delta P_{f}+\Delta P_{\text {in }}+\Delta P_{\text {out }}
$$

where,

$$
\begin{aligned}
& \Delta P_{f}=f \frac{L_{\text {th }}}{D} \frac{1}{2} \rho_{\text {avr }} V_{\text {avr }}^{2} \\
& \Delta P_{\text {in }}=\gamma \frac{1}{2} \rho_{\text {avr }} V_{\text {avr }}^{2} \\
& \Delta P_{\text {out }}=\frac{1}{2} \rho_{\text {avr }} V_{\text {out }}^{2}(1-x)
\end{aligned}
$$


where $f$ is the friction loss coefficient, $L_{t h}$ is airflow channel length, $D$ is the hydraulic diameter of the airflow channel, $\rho_{a v r}$ and $V_{a v r}$ are the average density and airflow speed respectively, $\gamma$ is the inlet loss coefficient and $x$ is the turbine pressure drop coefficient.

\section{Experimental setup}

The experiment setup, as shown in Fig. 2(a), is made up of four parts: the bracket, the electrical-simulated solar collector, the chimney and the adjust system. The bracket ensures to stabilize the table during the experiment. Solar radiation is simulated by electrical heating, and the circuit diagram is shown in Fig.3 (b). The angle of the collector could be changed by the adjustment system. The solar radiation data in this experiment is adapted from Lanzhou City. The solar radiation data used in the experiment are annually average global solar radiation from the National Meteorological Data Sharing Centre [7]. The conversion between the solar energy and electrical voltage is shown in Table 1. It is found from Table 1 that the MSR angle for Lanzhou is $30^{\circ}$.
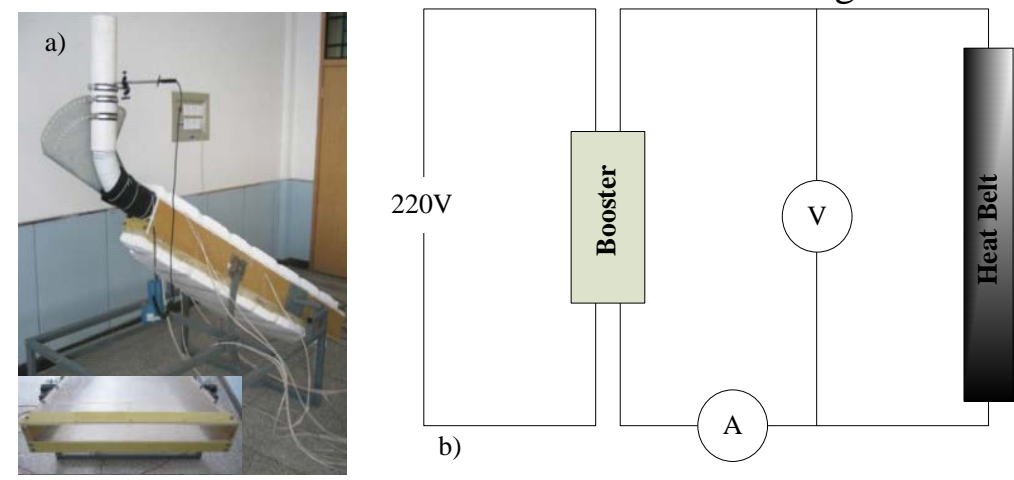

Fig. 2 Experiment setup: (a) the experimental components and (b)the circuit diagram Table 1. Conversion between the solar radiation and its matching voltage

\begin{tabular}{lll}
\hline Angle $\left(^{\circ}\right)$ & Solar radiation $\left(\mathrm{MW} \cdot \mathrm{m}^{-2}\right)$ & Voltage $(\mathrm{V})$ \\
\hline 20 & 620.6 & 173.3 \\
25 & 624.5 & 173.8 \\
30 & 625.3 & 173.9 \\
35 & 622.8 & 173.5 \\
40 & 617.1 & 172.8 \\
45 & 608.3 & 171.5 \\
50 & 596.3 & 169.8 \\
55 & 581.4 & 167.7 \\
60 & 563.6 & 165.1 \\
65 & 543.1 & 162.1 \\
70 & 520.1 & 158.6 \\
75 & 494.8 & 154.7 \\
\hline
\end{tabular}

\section{Results and discussion}

The air temperature rise, the air speed and the air mass flow are experimentally measured under different collector angles. The theoretically calculated temperature rise in the solar collector, the air speed at the outlet of the collector and the air mass flow rate in the chimney are compared with the experimental results in Fig. 3(a), (b) and (c) respectively. It is found from Fig. 3(a) that the temperature increases when the collector angle changes from $20^{\circ}$ to $75^{\circ}$. The differences between the simulation and experiment results are within 10\%. It is found from Fig 3(b) that the tendencies of the two groups of values are the same. There is a peak when the angle is near $53^{\circ}$. However, the differences between the calculated and experimented results are larger, reaching up to 20\%. One possible reason for this is the usage of the corrugated hose at the connection area of inclined solar collector and vertical chimney, which slows the airspeed down. Another possible reason is that the calculated temperature rise in the solar collector is smaller than that in the experiment, while the calculated airspeed is higher than that in the experiment. The corrugated hose slows down the 
airspeed and the air is heated at this area for a longer time. Fig. 3(c) shows the air mass flow in the chimney under different collector angle conditions. The simulated highest mass flow rate appears at $60^{\circ}$. And the experimental maximum air mass flow rate locates at $55^{\circ}$. It is thus concluded the MAF angle for the solar chimney system is near $60^{\circ}$. From Table 1 and Fig. 3(c), it is indicated that there is large difference between the MSR and MAF angles, as the MSR and MAF angles for Lanzhou are $30^{\circ}$ and $60^{\circ}$ respectively.

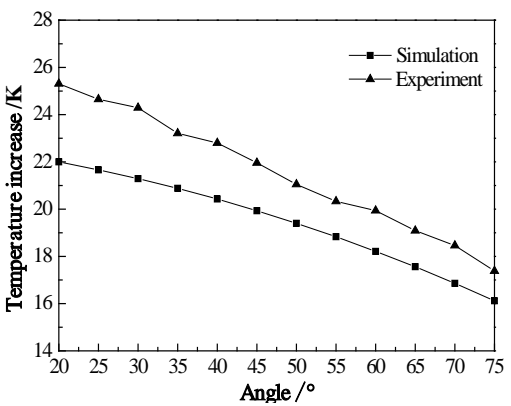

(a)

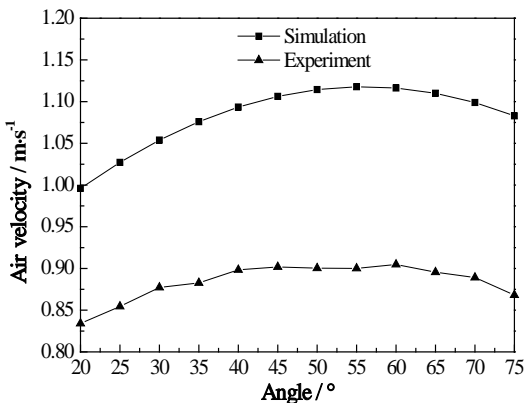

(b)

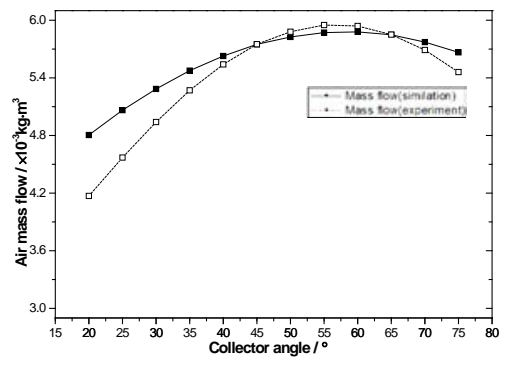

(c)

Fig. 3 Simulation and experiment results of (a) temperature rise in the collector, (b) airspeed at the collector outlet and (c) air mass flow inside the chimney

\section{Conclusions}

In this study, a mathematical model is built for the solar collector and solar chimney. An experimental setup is also built to valid the difference between the MSR and MAF angles. It is found from the experimental and analytical study that with the collector angle increasing, although the air temperature rise is decreasing at the collector outlet, the air mass flow generally decrease after a long-term increase. For Lanzhou City, the MAF angle for the solar collector is $60^{\circ}$, while the MSR angle for the solar chimney is $30^{\circ}$.

\section{Acknowledgements}

This research was funded by the National Natural Science Foundation of China (Nos.: 51506043 and 51206040), the Fundamental Research Funds for the Central Universities (Nos.: 2014B19714, 2013B19014 and 2011B11614).

\section{References}

[1] El-Maghlany, WM, Teamah, MA and Tanaka, H. Energy Conversion and Management Vol. 105 (2015), p. 1096-1104.

[2] Abbassi, F and Dehmani, L. Experimental and numerical study on thermal performance of an unvented Trombe wall associated with internal thermal fins. Energy and Buildings Vol. 105(2015), p. 119-128.

[3] Shojaeizadeh, E, Veysi, F and Kamandi, A. Exergy efficiency investigation and optimization of an $\mathrm{Al}_{2} \mathrm{O}_{3}$-water nanofluid based Flat-plate solar collector. Energy and Buildings Vol. 101(2015), p. 12-13.

[4] Schlaich J: The solar chimney: Electricity from the sun, (Maurer C, Geislingen, Germany 1995).

[5] Bilgen E and Rheault J. Solar chimney power plants for high latitudes. Solar Energy Vol. 79(2005), p. 449-458.

[6] F Cao, L Zhao and LJ Guo, Simulation of a sloped solar chimney power plant in Lanzhou. Energy Conversion and Management Vol 52(2011), p. 2360-2366. 
[7] National Meteorological Data Sharing Centre .Chinese Monthly Solar Radiation (1993-2000). http://cdc.cma.gov.cn. 